\title{
Categorias de entendimento do passado entre os Kadiwéu: narrativas, memórias e ensino de história indígena
}

The categories of understanding the past among Kadiwéu: narratives, memories and indigenous history teaching

Giovani José da Silva*

\section{RESUMO}

A existência da Lei 11.645/2008, que prevê a inserção do ensino de história e culturas indígenas na Educação Básica, por si só pode não ser a solução para acabar com a invisibilidade das populações indígenas dentro e fora das escolas brasileiras, mas representa um passo importante em direção ao reconhecimento de uma sociedade historicamente formada por diversas culturas e etnias. $\mathrm{O}$ artigo discute, com base nas categorias de entendimento do passado entre índios Kadiwéu de Mato Grosso do Sul, a articulação entre o ensino de história e culturas indígenas e a elaboração de memórias e narrativas. Ao se conhecer como determinado grupo indígena reconstrói o próprio passado e que categorias são utilizadas para narrar/rememorar tempos pretéritos, percebem-se outras formas de apreensão, compreensão e representação da história, o que enriquece sobremaneira o ensino da disciplina.

Palavras-chave: Ensino de História; índios Kadiwéu; passado.

\section{Abstract}

The existence of the 11645/2008 Law, which made mandatory the insertion of indigenous history and cultures teaching in the Basic Education, cannot itself be the solution to end the invisibility of indigenous peoples inside and outside of Brazilian schools, although it represents an important step towards recognition of a society historically formed by various cultures and ethnicities. This article discusses, based on the categories of understanding the past among Kadiwéu Indians from Mato Grosso do Sul, the relationship between the teaching of indigenous history and cultures and the development of memories and narratives. Being aware of how each indigenous group rebuilds its own past and which categories are used to narrate/recall past times, other forms of apprehension, understanding and representation of history are realized, which greatly enriches the teaching of this subject.

Keywords: History teaching; Kadiwéu Indians; past.

\footnotetext{
*Universidade Federal de Mato Grosso do Sul (UFMS), Campus de Nova Andradina. Caixa Postal 128. 79750-000 Nova Andradina - MS - Brasil. giovanijsilva@hotmail.com
} 
Ainda hoje, quando são lidos alguns livros didáticos de História tem-se a impressão de que as populações indígenas pertencem exclusivamente ao passado do Brasil. Os verbos relacionados aos índios invariavelmente estão no pretérito: 'caçavam', 'pescavam', 'dormiam em redes' etc., e a eles são dedicadas apenas algumas poucas páginas, geralmente na chamada 'pré-história' e/ou no 'cenário do descobrimento'. A partir da chegada dos portugueses ao continente americano, os indígenas desaparecem e os alunos não fazem a mínima ideia do que teria ocorrido nos séculos seguintes aos diferentes grupos (bem como aos seus descendentes) que habitavam as terras que viriam a se tornar o território brasileiro. Nesse sentido, a existência da Lei 11.645/2008, que prevê a inserção do ensino de história e culturas indígenas na Educação Básica, por si só pode não ser a solução para acabar com a invisibilidade das populações indígenas dentro e fora das escolas, mas representa um passo enorme em direção ao reconhecimento de uma sociedade historicamente formada por diversas culturas e etnias, dentre elas as indígenas.

Afinal, o Brasil é um país de rica diversidade pluricultural e multiétnica, embora muitos ainda tenham dificuldade em reconhecer tal situação, quando não a desconhecem quase que completamente ou a escamoteiam de propósito. A sociedade brasileira tem, em sua composição demográfica, diferentes matrizes étnicas e uma riqueza etnocultural que constituem um patrimônio a ser preservado e respeitado. Sobre a origem dos indígenas, há dúvidas que aos poucos vão sendo esclarecidas, especialmente pela Arqueologia, a Antropologia Física e a História Indígena. A respeito das sociedades nativas da atualidade, sabe-se que pertencem a diferentes famílias e troncos linguísticos e formam um contingente populacional de menos de 1 milhão de indivíduos autodeclarados, de acordo com o último censo realizado no país pelo Instituto Brasileiro de Geografia e Estatística (IBGE), em 2010. ${ }^{1}$

Hoje, mais de 180 línguas indígenas são faladas por aproximadamente 240 sociedades diferentes ${ }^{2}$ que vivem nos mais distintos pontos do país. Seus territórios, em conjunto, recobrem uma área de pouco mais de 13\% do Brasil. Toda essa sociodiversidade traduz-se em rituais, cosmologias, tradições, manifestações artísticas e culturais peculiares a cada grupo. A maioria dessas sociedades indígenas concentra-se na Amazônia, embora existam numerosas populações no Centro-Sul e no Nordeste. Entretanto, pouco ainda se conhece 
sobre tais diferenças, e o senso comum - como muitos materiais didáticos, aliás - insiste em atribuir a essas populações a genérica e colonial categoria de 'índios', como se fossem todos iguais: 'habitantes de ocas', 'adoradores de Tupã', 'antropófagos' etc.

Aos poucos, o Ensino Superior brasileiro está incorporando mudanças que buscam promover um melhor conhecimento a respeito da realidade indígena no país, seja no passado ou no presente. Todos os cursos de licenciatura - ou seja, de formação de professores - deveriam atentar para o fato de que a Lei 11.645/2008 não delega apenas aos professores de História a tarefa de ensinar sobre história e culturas indígenas. O que se vê, contudo, é outra realidade: os cursos de História, de Norte a Sul do Brasil, têm procurado suprir a necessidade de oferecer disciplinas, tais como História da África ou História Indígena. Tais iniciativas esbarram na ausência de profissionais qualificados para atender a demanda criada pela lei, e muitos acabam por improvisar, prestando um desserviço à educação de crianças, adolescentes e jovens.

Assim, as dificuldades de professores e demais profissionais da Educação Básica consistem, particularmente, em responder à questão de como caracterizar com clareza e correção as sociedades indígenas em seus aspectos comuns, ressaltando, entretanto, a singularidade de cada uma delas, sem reforçar estereótipos e preconceitos. Nesse caso, afirmam especialistas, é fundamental indicar a diversidade significativa que há entre as sociedades indígenas localizadas no Brasil (e em outros lugares das Américas e do mundo), em termos de adaptação ecológica a diferentes ambientes e, também, em termos sociais, políticos, econômicos, culturais e linguísticos. ${ }^{3}$

O objetivo principal deste artigo é, pois, contribuir para a reflexão sobre os desafios e as possibilidades da História Indígena na Educação Básica, estimulando professores e estudantes a pensar sobre as sociedades indígenas que vivem ou viveram no Brasil e o que se escreve a respeito delas. Com base em experiências vivenciadas no estado de Mato Grosso do Sul, entre os índios Kadiwéu, e em suas categorias de entendimento do passado, revela-se possível e necessário abordar nas escolas não indígenas a história dos índios, retirando-os do esquecimento ou do 'passado perpétuo' a que ficaram relegados por tanto tempo. 


\section{A LITERATURA CIENTÍfICA RECENTE SOBRE QUESTÕES INDÍGENAS}

Como prova dos esforços empreendidos por antropólogos e outros pesquisadores brasileiros para divulgar, a um público cada vez maior, informações mais corretas e atualizadas a respeito das sociedades indígenas, na década de 1990 foram lançadas inúmeras obras de cunho didático sobre tais questões no Brasil. Destacam-se, nesse panorama, Índios no Brasil ${ }^{4}$ e A temática indígena na escola. ${ }^{5}$ Esses importantes trabalhos vieram se somar ao pioneiro livro Índios do Brasil (1993), do antropólogo Julio Cezar Melatti, publicado no início da década de $1970 .{ }^{6}$ Além dessas obras, destaca-se, também, o trabalho de divulgação da antropóloga Joana Aparecida Fernandes Silva (Joana Fernandes), intitulado Índio: esse nosso desconhecido (1993). ${ }^{7}$

Ainda na década de 1990, no marco das comemorações dos 500 anos da chegada de Cristóvão Colombo às Américas - o chamado V Centenário -, foi lançada a coletânea História dos índios no Brasil (1992), ${ }^{8}$ organizada pela antropóloga Manuela Carneiro da Cunha. A obra contou com a colaboração de antropólogos, linguistas e historiadores, entre outros pesquisadores, e tornou-se uma referência dentro e fora do país.

A respeito do V Centenário, John Manuel Monteiro já observou criticamente que:

De fato, tanto na sua comemoração quanto no seu repúdio ... colocou em xeque um sem-número de termos já convencionais no léxico do historiador. Para uns, sobretudo os panfletários e os adeptos de uma postura politicamente correta, a solução foi a de banir de vez termos como descobrimento, Novo Mundo e mesmo indios, substituindo-os por neologismos que, frequentemente, incorrem no erro de introduzir novos e maiores equívocos. Outros têm buscado um caminho mais profícuo para suas revisões historiográficas, incorporando perspectivas teóricas de outras disciplinas, tais como a antropologia, a arqueologia e a linguística, entre outras, para produzir uma visão crítica e cada vez mais complexa dos processos demográficos, políticos, econômicos, sociais e, sobretudo culturais que resultaram naquilo que se chama de América Latina. ${ }^{9}$

No início dos anos 2000 divulgou-se uma série intitulada "Antropologia e Educação", na qual foram publicados os seguintes títulos: Antropologia, História e Educação, Práticas pedagógicas na escola indígena, Ideias matemáticas 
de povos culturalmente distintos e Crianças indígenas. ${ }^{10}$ Mais recentemente, Maria Regina Celestino de Almeida lançou Os índios na história do Brasil, ${ }^{11}$ em que traça um panorama da presença indígena na história da antiga colônia portuguesa, hoje Brasil, entre os séculos XVI e XIX. Em 2011, os arqueólogos Pedro Paulo Funari e Ana Piñon publicaram A temática indígena na escola. ${ }^{12}$

Há, também, na internet um site mantido pela organização não governamental ISA (Instituto Socioambiental) em que se pode encontrar a Enciclopédia dos Povos Indígenas Brasileiros, com informações atualizadas e escritas por especialistas. ${ }^{13}$ Tudo isso mostra que há um esforço empreendido para se reunir e oferecer conhecimentos a respeito da presença indígena no passado e no presente do país. Contudo, em que pese à boa qualidade de todas as publicações citadas, pode-se dizer que tais questões ainda se encontram distantes das escolas, em todos os quadrantes no Brasil, inclusive em Mato Grosso do Sul, um Estado considerado eminentemente 'indígena', onde vivem atualmente os Kadiwéu.

Nas palavras de Funari e Piñon:

A escola, ao longo da história do Brasil, tem cristalizado determinadas imagens sobre os índios que 'fazem a cabeça' dos cidadãos presentes e futuros. Com isso, muitas vezes, acabam favorecendo a exclusão ou, pelo menos, o esmaecimento da presença indígena na sociedade e na cultura brasileiras ... Entretanto, se houver vontade política para tanto, é inegável o papel que a escola pode ter no sentido de atuar para uma maior compreensão do quanto o Brasil deve aos índios e como se enriquece, em termos culturais, com essa experiência. (2011, p.8)

Desde a infância, jovens brasileiros infelizmente ainda convivem com as estereotipadas imagens do 'índio genérico’ (expressão cunhada por Darcy Ribeiro) e alimentam inúmeras fantasias sobre o que consideram espécies de 'fósseis humanos'. Apesar de muitos dos livros didáticos, adotados atualmente no Ensino Fundamental e no Ensino Médio, insistirem em retratar as populações indígenas no Brasil como pertencentes, exclusivamente, ao passado, é mais do que saudável referir-se a essas sociedades no contexto do Brasil contemporâneo - é necessário. Isso porque, se inúmeros grupos indígenas desapareceram no país ao longo de mais de 500 anos - desde a chegada dos portugueses e espanhóis a terras americanas -, é verdade também que muitos 
sobreviveram, lutando por direitos históricos e por uma maior visibilidade, a fim de que esses direitos sejam garantidos e respeitados.

\section{DESAFIOS E PERSPECTIVAS DA HISTÓRIA INDÍGENA NO BRASIL}

Recentemente, em março de 2008, foi sancionada pela presidência da República a Lei 11.465/2008 que tornou obrigatória a inclusão de aulas de história e cultura das populações indígenas para alunos dos Ensinos Fundamental e Médio de escolas públicas e particulares do país. A medida vem sendo implantada de forma gradual nas escolas, sem que haja a necessidade de mudanças radicais nas matrizes curriculares, uma vez que não se criou uma nova disciplina. A história e a cultura das populações indígenas, assim como das afro-brasileiras e africanas (garantidas anteriormente pela Lei 10.639/2003), tornou-se um tema transversal aos já abordados em disciplinas tais como História, Geografia, Artes e Literatura. Espera-se que com essa medida - além de outras - reverta-se, paulatinamente, um quadro sombrio de desconhecimento a respeito da presença de sociedades que há muito tempo vivem no território brasileiro e que sobreviveram física e culturalmente ao longo do tempo, lutando até mesmo contra o próprio extermínio.

Em 1970, Darcy Ribeiro publicou em Os índios e a civilização ${ }^{14}$ um levantamento sobre a situação do conjunto da população indígena no país na primeira metade do século XX. Apesar dos erros já verificados por inúmeros pesquisadores na lista de grupos considerados 'extintos' por Ribeiro (tais como os Guató, Kinikinau e Ofayé, que vivem atualmente em Mato Grosso do Sul, por exemplo), o estudo consistiu em um instigante 'roteiro exploratório', como preferiu designar o próprio autor. Em seu texto, o antropólogo chamou a atenção para a situação das populações indígenas no Brasil em dois momentos históricos: em 1900 e em 1957.

Os resultados, bastante desanimadores na época, apontavam para o acelerado e contínuo desaparecimento das sociedades indígenas, ideia que já vinha sendo disseminada desde o século retrasado, pois, como afirma John M. Monteiro, "Sobretudo a partir do século XIX, a perspectiva que passava a predominar prognosticava, mais cedo ou mais tarde, o desaparecimento total dos povos indígenas". ${ }^{15}$ A ideia de extinção dos indígenas ainda persiste com força nas escolas brasileiras apesar de os prognósticos fatais, felizmente, não terem se 
confirmado. Ao contrário do que previu Ribeiro, as sociedades indígenas não desapareceram, pois muitas delas consideradas 'extintas' reapareceram no cenário étnico do país, nos últimos anos.

Outro equívoco também bastante presente é a chamada 'aculturação', uma sedutora ideia de que no contato com a população não indígena os índios foram 'perdendo' ao longo do tempo sua cultura, tornando-se 'menos índios', portanto. As teorias da aculturação previam o gradual desaparecimento dos grupos étnicos, que seriam incorporados, em menor ou maior grau, ao grupo majoritário não índio. Egon Schaden, ${ }^{16}$ por exemplo, referiu-se a processos de mudança decorrentes dos contatos entre grupos culturalmente diversos, nos quais a aculturação seria o conjunto de transformações das sociedades indígenas em contato com populações não indígenas. De acordo com Fernandes (1993, p.17-18), entretanto, “A teoria da aculturação, muito difundida entre nós, vem sendo questionada pela antropologia desde a década de [19]70”.

À luz da ideia de aculturação desconsidera-se, portanto, o longo período de contato a que foram submetidas diversas sociedades indígenas de todo o país, desde os tempos da colonização ibérica. A intenção é clara: ao se desqualificar os indígenas como 'bugres', 'aculturados' ou mesmo 'não reconhecidos', permite-se que essas sociedades sejam usurpadas em seus direitos históricos. Essas informações ainda são repassadas nos bancos escolares, da Educação Básica ao Ensino Superior, e muitas vezes recebem a chancela de pesquisadores que as reproduzem em obras que versam sobre a temática. Desconhecem-se, assim, línguas e culturas, bem como as trajetórias espaciais e temporais vividas por essas sociedades.

A atitude de se qualificar muitas das populações indígenas do presente como 'aculturadas', ou seja, como se houvesse populações 'mais indígenas' e outras 'menos indígenas', remete a uma espécie de escala evolutiva, em que os critérios para a definição de quem é ou não índio passam pela desaparição da língua indígena como língua materna; pelo uso de roupas, calçados e outros elementos exteriores à cultura material tradicional dessas populações; ou, ainda, pelo uso de recursos tecnológicos modernos, tais como telefones celulares e computadores. Isso sem contar os traços biológicos, que para muitas pessoas são utilizados como critério definidor de quem é indígena ou não no Brasil, até os dias de hoje. Deseja-se, assim, que grupos que vivem em pleno século 
XXI sejam fisicamente semelhantes aos seus antepassados de séculos anteriores e comportem-se exatamente como eles.

Ao se imaginar que essas populações devam exibir comportamentos ou elementos de cultura material de tempos remotos, desconsidera-se praticamente toda a trajetória histórica dos indígenas, marcada por resistências, fugas, capitulações, negociações e tentativas de extermínio. Isso tudo sem contar os grupos que se mantiveram isolados ou ocultos sob uma identidade não indígena, a fim de evitarem perseguições e poderem, assim, se reproduzir física e culturalmente, ainda que com grandes dificuldades. Contrariando, pois, as expectativas de muitos, nos últimos anos, verifica-se o 'surgimento' ou 'ressurgimento’ de indígenas, sobretudo na região Nordeste do Brasil. ${ }^{17}$

Com isso, verifica-se que o número de grupos indígenas no Brasil poderá até mesmo aumentar nos próximos anos, o que caracteriza uma situação inusitada e bastante complexa. Apenas para se ter uma ideia, a publicação Povos indígenas no Brasil, veiculada pelo ISA em parceria com organismos nacionais e internacionais, em suas quatro últimas edições - 1996, 2000, 2006 e 2011 registrou os seguintes números: 206 sociedades indígenas em 1996 (Ricardo, 1996); 216 em 2000 (Ricardo, 2000), 225 em 2006 (Ricardo; Ricardo, 2006) e 235 em 2011 (Ricardo; Ricardo, 2011). ${ }^{18}$ Isso não significa, absolutamente, que antropólogos ou outros pesquisadores estejam ‘inventando' etnias pelo Brasil afora, mas que, num curto período de 15 anos, surgiram quase trinta grupos reivindicando para si uma identidade étnica, autoafirmando-se indígenas e alimentando o desejo de serem vistos e reconhecidos como tais. Alguns desses grupos 'ressurgiram' em Mato Grosso do Sul, como os Kamba e os Kinikinau, estes últimos convivendo durante muito tempo entre os Kadiwéu.

Em Mato Grosso do Sul, estado da região Centro-Oeste que possui uma das maiores populações indígenas do Brasil, as questões indígenas ainda são tratadas na maioria das escolas da mesma forma como se verifica em muitos outros recantos do país. Em geral, fala-se sobre os índios apenas no mês de abril, próximo ao dia 19, e é comum ainda se repetirem com os alunos antigos 'rituais' pedagógicos, tais como enfeitá-los com cocares feitos de cartolina e penas de aves domésticas ou saiotes de estopa. No restante do ano letivo trata-se o indígena com um silêncio perturbador, e o máximo de contato que crianças, adolescentes e jovens terão com o tema será por meio da mídia, especialmente da televisão. Nesse veículo de comunicação, em geral, as imagens das 
populações indígenas estão associadas apenas a desnutrição, violência, suicídios, 'invasões' etc. Em resumo, assim como em tantas outras escolas de Norte a Sul do Brasil, os alunos sul-mato-grossenses desconhecem a rica diversidade étnica que existe no estado, que conta hoje com pelo menos dez etnias: Atikum, Chamacoco, Guarani (Kayowá e Ñandeva), Guató, Kadiwéu, Kamba, Kinikinau, Ofayé e Terena.

Cada um desses grupos possui uma trajetória histórica única e rica em tradições culturais, em que pese o tempo de contato com os não indígenas e as dificuldades de reprodução física e cultural. Há grupos que migraram de outros Estados, como é o caso dos Atikum, que são de Pernambuco e até mesmo de outros países, a exemplo dos Kamba, originários da Bolívia. Há grupos relativamente numerosos, como os Guarani e Terena, e alguns compostos por menos de cem pessoas, como é o caso dos Ofayé e dos Chamacoco. Há até mesmo os que vivem na luta por serem reconhecidos, pois foram considerados 'extintos' tempos atrás - Guató e Kinikinau, por exemplo. Dentre os grupos indígenas localizados hoje em Mato Grosso do Sul, há também os Kadiwéu, famosos pela cerâmica que suas mulheres fabricam e pela fama de 'guerreiros' de seus homens. ${ }^{19}$

\section{CATEgorias DE ENTENDimento do PASSAdo ENTRE OS KadiWÉU}

O autor do presente artigo acompanhou a instalação de escolas entre os Kadiwéu e foi professor dos Ensinos Fundamental e Médio da unidade escolar localizada na aldeia Bodoquena, entre 1997 e 2004. No início havia um grande desafio a ser vencido: a questão da língua. Os Kadiwéu falam um idioma filiado linguisticamente à família Guaikuru, única no Brasil. Homens e mulheres se expressam utilizando distintas variações dialetais dessa língua, o que provoca ainda mais confusão para um não falante. ${ }^{20}$ Os Kadiwéu se dividem em estratos sociais: os Otagodepodi ou 'senhores' (considerados 'puros') e os Niotagipe ou 'cativos' (descendentes de índios de outras etnias e, portanto, na visão Kadiwéu, considerados 'misturados'). Toda essa situação configurou-se numa rica experiência docente, marcada por uma perspectiva fundamental, apreendida em um dos textos de Circe M. F. Bittencourt (1994): a de ser possível uma aproximação entre membros de distintas culturas, em um movimento de enriquecimento mútuo, frutífero tanto para o Ecalailegi ('não índio', em língua 
Kadiwéu) como para os Ejiwajegi ('os verdadeiros índios') que se encontravam na mesma sala de aula. ${ }^{21}$

No início, não havia energia elétrica ou água potável na aldeia dos Kadiwéu, mas não faltavam o desejo e a curiosidade de se conhecer e compreender o Outro. Como ressalta Bittencourt:

o conhecimento do 'outro' é a possibilidade de aumentar o conhecimento sobre si mesmo, à medida que conhece outras formas de viver, as diferentes histórias vividas pelas diversas sociedades. Conhecer o outro significa comparar situações, e nesse processo comparativo o conhecimento sobre si mesmo e sobre seu grupo aumenta consideravelmente. (1994, p.115)

Contudo, as coisas nem sempre tinham ocorrido assim na história da Educação Escolar daqueles indígenas. O processo de ensino e aprendizagem do componente curricular escolar História entre os Kadiwéu (e com outros tantos grupos indígenas localizados no Brasil) foi marcado pelo insistente uso de técnicas de memorização de datas, nomes e fatos completamente alheios à realidade em que viviam os indígenas. Além disso, há que se considerar a violência física e psicológica sofrida por eles em âmbito escolar por anos a fio, pelo menos até meados da década de $1990 .{ }^{22}$ Toda essa situação, somada à proibição de se falar o idioma Kadiwéu dentro da escola, durante décadas, causou um profundo desinteresse por parte da comunidade indígena pela escolarização formal. Havia altos índices de repetência e evasão, demonstrando que o modelo adotado era ineficaz e traumatizante. As primeiras tentativas de mudar essa situação em sala de aula foram frustradas pelas expectativas de pais e alunos de que os castigos continuariam como forma de se 'educar', mesmo jovens e adultos. Entretanto, os Kadiwéu foram percebendo, de forma gradual, que a escola poderia ser diferente do 'cemitério' que a consideravam até então. ${ }^{23}$

Crê-se ser a principal tarefa de um professor de História em escolas indígenas (e não indígenas, também), mais do que ensinar datas, nomes, fatos ou conceitos, ajudar os alunos a perceberem que eles fazem parte de uma história e que há diferentes formas de se contar histórias. Além disso, aprende-se também a pensar historicamente, percebendo como indígenas e não indígenas reconstroem o passado. Os Kadiwéu, por exemplo, acreditam que há 'histórias de admirar' e 'histórias que aconteceram mesmo'. ${ }^{24}$ A diferença entre elas reside no fato de que na primeira categoria estão aquelas histórias que 
não precisam de comprovação, pois são contadas para provocar o espanto, a admiração de quem as escuta. Na outra categoria estariam histórias contadas pelos mais velhos e apenas a confiança na palavra destes seria suficiente para que se acredite nelas.

De acordo com a antropóloga Mônica T. S. Pechincha:

Os Kadiwéu diferenciam pelo menos duas categorias de narrativas ... parte delas pode ser classificada imediatamente na categoria de mitos, aquelas que os Kadiwéu chamam de 'histórias de admirar', ou 'histórias que fazem milagres', ou 'exemplos de primeira indiada'. São histórias 'sagradas', já que 'sagrado' foi um qualificativo atribuído pelos próprios índios. Referem-se a um tempo não localizável no tempo cronológico, a não ser como tempo fundante.

Um outro tipo de narrativas seria aquele que reúne histórias que, segundo os informantes, são 'histórias que aconteceram mesmo'. Nessa categoria, incluem-se as narrativas sobre guerras contra outros povos, a memória de um passado que se apresenta como 'descrição histórica' de determinados acontecimentos. (1994, p.80)

Dentre as 'histórias que aconteceram mesmo', os Kadiwéu ressaltam notadamente a Guerra do Paraguai (1864-1870), que teve intensa participação indígena, infelizmente esquecida pelos manuais didáticos de História do Brasil. O que mais impressiona em relação à memória dos Kadiwéu sobre o conflito platino é a ideia de que a guerra jamais tenha terminado e que a qualquer momento os brancos possam novamente precisar da ajuda dos 'índios cavaleiros' para derrotar os inimigos. ${ }^{25}$

Uma terceira categoria pode ser acrescentada às duas anteriormente apresentadas: a História que hoje se aprende nos bancos escolares como disciplina e 'inventada' pelos não índios. A característica dessa história escolar seria, segundo os indígenas, a 'obsessão' pelas fontes, por documentos escritos como provas a respeito do passado. A história, contida em livros e manuais, supervalorizaria o escrito e desprezaria aquilo que é transmitido oralmente de uma geração à outra. Os Kadiwéu acreditam ser importante conhecer a história 'inventada' pelos 'brancos' como forma de entenderem melhor as representações construídas pelo Outro sobre tempos pretéritos em outros espaços (a Europa, por exemplo, de onde vieram os portugueses e espanhóis com cavalos e outros animais desconhecidos pelos indígenas). 
Além disso, haveria a possibilidade de existir uma quarta categoria, em que os índios criariam histórias apenas para contarem a pesquisadores 'brancos', ávidos por informações e que volta e meia perambulam por suas terras. ${ }^{26}$ Tais perspectivas permitem ao docente e aos alunos vivenciar a escola como uma verdadeira fronteira entre dois ou mais modos de aprender e ensinar, entre mundos distintos que podem e devem dialogar entre si. ${ }^{27}$ Tal diálogo não ocorre, entretanto, sem alguns atritos, dúvidas, questionamentos e sobressaltos. Os indígenas, pelo menos desde a década de 1970, têm reivindicado uma escola fundamentada em suas tradições e que revele seus modos peculiares de viverem a vida e representarem-na. Nas palavras do historiador Paulo Humberto Porto Borges:

Um possível projeto escolar que represente as tradições desses povos só será possível se os professores forem indígenas e utilizarem metodologia e material elaborados a partir de seus próprios referenciais culturais. Os projetos de educação escolar indígena que não compreenderem essa necessidade, serão semelhantes às antigas escolas rurais 'para índios' mantidas pela Funai. ${ }^{28}$

É chegada a hora, portanto, de se tentar uma aproximação maior com o universo sociocultural indígena, procurando enxergar a multiplicidade, a pluralidade, a diversidade étnica e cultural existente nele, representada pela existência de mais de duzentas diferentes formas de se viver e representar esse viver. Não apenas a escola indígena pode ser vista como uma fronteira entre dois ou mais mundos distintos, mas a própria instituição escolar não indígena também pode se abrir para o Outro, promovendo o respeito pelas diferenças. Afinal, o diálogo intercultural ocorre precisamente nesse encontro/desencontro/confronto entre ideias e lógicas de pensamento distintas, porém não necessariamente excludentes.

ENSINO DE HISTÓRIA EM UMA ESCOLA INDÍGENA DE EDUCAÇÃo BÁSICA: BREVE RELATO DE UMA 'AVENTURA'

Os índios Kadiwéu se autodenominam Ejiwajegi e são os descendentes, no Brasil, dos antigos Mbayá-Guaikuru, os célebres 'Índios Cavaleiros', tendo em vista a destreza com que utilizavam o cavalo em incursões guerreiras entre 
os séculos XVII e XIX. No começo do século XX já se encontravam nas terras da Reserva Indígena Kadiwéu, uma área de aproximadamente 538.536 hectares demarcada definitivamente desde a década de 1980, no município sul-mato-grossense de Porto Murtinho, região do Pantanal. Hoje, vivem distribuídos em quatro das aldeias localizadas na Reserva: Barro Preto, Bodoquena, Campina e Tomázia.

Sabe-se da existência de escolas presentes nas aldeias Kadiwéu desde a década de 1940. O primeiro contato do autor com esse povo indígena ocorreu em 1997, na maior aldeia da Reserva, a Bodoquena. Saindo de São Paulo, capital, foi para Porto Murtinho a fim de ministrar aulas na rede pública municipal de ensino. Como esteve envolvido com questões indígenas desde o início do curso de graduação em História (concluído na UFMS/Campus de Aquidauana, em 1995), foi chamado para avaliar a situação escolar dos índios. Em um ano de contato sistemático observou que as escolas presentes na Reserva eram precárias e não correspondiam aos anseios das comunidades. Passou, então, a colaborar com a Prefeitura para regularizar a situação das escolas, de modo que fizessem parte da Rede Municipal de Ensino de Porto Murtinho.

Em dezembro de 1998 foi criada por Lei Municipal a Escola Municipal Indígena "Ejiwajegi" - Polo, na aldeia Bodoquena, e Extensões nas demais aldeias. Entretanto, não era apenas a regularização da escola que estava em jogo: os índios Kadiwéu e Kinikinau (estes últimos moradores da aldeia São João) mostravam-se descontentes com o fato de que os estudos nas aldeias se encerravam na $4^{\mathrm{a}}$ série do Ensino Fundamental. Quem desejava continuar estudando deveria procurar a cidade e, por essa razão, muitos paravam de estudar. O impasse foi parcialmente resolvido no ano 2000, quando o autor pediu sua transferência para a recém-criada escola. Previam-se dificuldades desde o início, pelo fato de ser um não índio em contato direto em sala de aula com crianças indígenas, falantes de outro idioma e com costumes diversos.

A vinda do sociólogo José Luiz de Souza (Wanixogowe, 'o pássaro que voa alto'), de Santo André (SP), para acompanhar aquela 'aventura' pedagógica ajudou muito. Não havia outros professores não índios dispostos a ministrar aulas na aldeia, por causa das dificuldades (falta de energia elétrica e água potável, difícil acesso etc.) e do preconceito. No tocante à disciplina História, o desafio sempre foi o de mostrar aos Kadiwéu que as culturas indígenas são importantes, revelando os modos de ser e viver desses povos, e que precisam 
ser valorizadas a fim de não caírem no esquecimento e serem substituídas, sem reflexão, pelos usos e costumes dos não índios. Para os Kadiwéu da aldeia Bodoquena a escola sempre havia sido o lugar para se aprender as coisas dos 'brasileiros' (é assim que eles se referem aos não índios ou Ecalailegi) e de receber castigos.

Percebia-se neles que sempre esperavam por maus tratos e que o ensino de História ministrado, até então, era marcado pela 'decoreba' de datas, fatos e personagens completamente alheios à realidade em que viviam. Não havia, até aquele momento, espaço para a reflexão e nem mesmo para um estudo de quem eram eles próprios ou o que os diferenciava dos não índios. Assim, os objetivos de ensino e aprendizagem iniciais foram: identificar relações sociais no próprio grupo de convívio, na localidade, na região, e outras manifestações estabelecidas em outros tempos e espaços; compreender que as histórias individuais são partes integrantes de histórias coletivas; dominar procedimentos de pesquisa escolar e de produção de textos, aprendendo a observar, colher e sistematizar informações.

Quanto ao conteúdo curricular ensinado, estabeleceu-se o seguinte: como surgiram o povo Kadiwéu e outros povos; como viviam os Ejiwajegi antigamente; diferenças entre os índios e entre índios e não índios. Inicialmente, houve conversas sobre os 'tempos de antigamente' (essa expressão é utilizada para referências ao passado), e os alunos indígenas foram estimulados a falar sobre tudo o que sabiam. Muitas histórias foram relatadas, acompanhadas de expressões, tais como "Meu avô me contou...". Com base nisso, resolveu-se que as pessoas mais velhas da aldeia seriam entrevistadas pelos próprios alunos. Foram sugeridos, então, seis temas: Moradia, Vestuário, Brinquedos, Alimentação, Guerras e Luto, e cada um escolheu um ou mais temas para pesquisar. Os alunos foram para as entrevistas e voltaram com muitas histórias, que socializaram com os colegas. Dentre essas histórias, contou-se o mito de criação dos Kadiwéu: eles acreditam terem sido tirados pelo Criador (Aneotedogoji), assim como toda a humanidade, de dentro de um buraco.

Variações do mito surgiram durante as apresentações dos resultados das entrevistas, e isso estimulou o autor a falar com eles sobre o surgimento da espécie humana. A escola havia recebido um livro didático e aproveitou-se um dos capítulos para conversar sobre o aparecimento de homens e mulheres. Foi interessante perceber que mesmo entre os alunos indígenas protestantes existia 
a ideia de que se homens e mulheres vieram de Adão e Eva, estes devem ter sido tirados de um buraco! Não houve intenção de desqualificar nenhuma das interpretações (mítica, religiosa ou científica), mas de conhecê-las, compreendê-las e discuti-las. Após essa atividade, propôs-se aos alunos refletir sobre as diferenças entre as pessoas e entre os grupos humanos.

Os alunos sentiram que o conhecimento sistematizado por eles sobre o povo indígena do qual faziam parte tem tanto valor quanto os conhecimentos adquiridos nos livros dos 'brasileiros'. Com isso, identificaram relações sociais no próprio grupo de convívio, na localidade e na região em que vivem. Perceberam, também, modos de vida muito diferentes que os Ejiwajegi desenvolveram em outros tempos e espaços. Puderam compreender que as histórias individuais coletadas eram partes integrantes da história dos Kadiwéu. O mais importante é que tomaram conhecimento e aplicaram procedimentos de pesquisa escolar em História e de produção de textos, em que puderam aprender a observar, colher e sistematizar informações, tornando-se (nas palavras dos próprios alunos) 'antropólogos de si mesmos'.

A avaliação dos resultados foi feita em sala de aula, quando da exposição oral das entrevistas, da socialização e sistematização dos conhecimentos adquiridos e da confecção de desenhos, como também mediante prova escrita bilíngue, em que se solicitou aos alunos uma síntese do que haviam aprendido. Se o diagnóstico inicial não foi exatamente animador, o mesmo não se pode dizer dos resultados obtidos por meio dessa experiência de ensino com os Kadiwéu nas aulas de História. Trabalhando o conceito de diferença, todos compreenderam que não eram inferiores aos não índios, mas únicos e particulares. Ao tornarem-se 'antropólogos de si mesmos', os Kadiwéu descobriram uma sociedade rica em tradições, que há muito vive em contato com os não índios, que enfrenta problemas com invasores de suas terras até hoje e vive um contínuo processo histórico do qual eles próprios fazem parte.

Anos de castigos físicos e psicológicos na escola, porém, deixaram marcas profundas entre os Kadiwéu. Vencer essa primeira resistência foi outro grande desafio que se impôs ao trabalho como professor não índio. O autor sentiu que havia sido aceito não somente quando homens e mulheres Kadiwéu, pais das crianças e jovens, pintaram as paredes da escola com motivos da arte daquele povo, mas especialmente quando o batizaram de Oyatogoteloco ('a luz que brilha longe', no idioma Kadiwéu) e afirmaram que quando seus filhos 
estivessem dando aulas para as gerações futuras, a história de Oyatogoteloco e de Wanixogowe entre eles seria contada dentro e fora da escola.

Os Kadiwéu, enfim, descobriram e sentiram o quanto é bom ser índio e conhecer a própria história. Tornando-se, momentaneamente, estranhos a si mesmos, ganharam confiança para refletir e mostrar o que foram, o que são e o que desejam ser. Com essa verdadeira 'aventura' pedagógica foi possível enxergar melhor nos alunos indígenas, tão diferentes dos não índios e ao mesmo tempo tão semelhantes, a riqueza da diversidade étnica e cultural do Brasil. A experiência rendeu ao autor o Prêmio Victor Civita 2001 - Professor Nota 10, na categoria Escola Pública.

\section{CONSIDERAÇÕES FINAIS}

Escolas em aldeias, índios alfabetizados em suas próprias línguas e por meio de processos próprios de aprendizagem, utilizando-se de telefones celulares, conectados à internet e participando de redes sociais: para muitos, ainda, tais imagens não correspondem ao que se espera de um modus vivendi 'autenticamente' indígena. A imagem estereotipada, veiculada em cartazes nas escolas públicas e privadas Brasil afora, nas propagandas de televisão ou em campanhas públicas, ainda insistem em mostrar índios de tangas, com arcos e flechas, sempre associados à ideia de que fazem parte apenas da natureza, sendo todos puros e dóceis. Porém, no início do século XXI há índios ingressando até mesmo na carreira política, realizando cursos de graduação e de pós-graduação, ocupando espaços onde antes sua presença era considerada inimaginável.

A inserção de indígenas na esfera política tem levado muitas pessoas a acreditarem que membros das diversas sociedades indígenas no Brasil não sejam mais índios 'de verdade'. Enquanto no país se conhece pouco das sociedades indígenas, a Funai indica a existência de alguns grupos isolados, sem contato intensivo com não índios, na Amazônia. Isso sem contar com os novos/velhos problemas que os indígenas enfrentam atualmente: epidemias, invasões de terras, alcoolismo, desnutrição, suicídios, êxodo para as cidades, inculcação de valores religiosos não tradicionais etc. Esses problemas compõem um quadro às vezes sombrio e desesperançoso para esses grupos. Porém, há motivos de esperança: o crescimento demográfico real de muitas sociedades 
indígenas tem sido enorme nas últimas décadas. Como visto, muitas delas, dadas como 'extintas' ou 'em vias de extinção', 'ressurgem' e, ao fazerem isso, se mostram dispostas a lutar pela garantia dos direitos conquistados na Constituição de 1988. Afinal,

Reconstruir a história para construir o futuro é algo que está, sem dúvida, na agenda de uma parte expressiva do movimento indígena atual; porém, é uma tarefa que exige uma reconfiguração radical das noções ainda prevalecentes na história que se ensina hoje. Assim, o caminho pela frente ainda é longo, até porque ... o caminho para o passado também está cheio de obstáculos. ${ }^{29}$

Contudo, salienta-se que a ideia de se tratar tais grupos indígenas como 'ressurgidos' ou 'emergentes' tem desagradado aos próprios índios. Segundo muitos, essas expressões mascaram a dura realidade sofrida por eles próprios e por seus antepassados, ao longo do tempo, tentando sobreviver a toda sorte de dificuldades. As expressões 'ressurgidos' e/ou 'emergentes' dão a ideia de que determinadas populações teriam 'desaparecido' ao longo da conquista e colonização ibéricas (e mesmo em séculos seguintes) e que no final do século XX e início do XXI estariam 'ressurgindo' ou 'emergindo', em um processo de 'geração espontânea'! Nada mais falso, quando se verifica, por exemplo, a trajetória histórica da população Kamba, dentro e fora das atuais terras sul-mato-grossenses. ${ }^{30}$ Por essa razão, esse e outros grupos indígenas têm adotado a expressão 'resistentes' em diversos documentos oficiais divulgados nos últimos anos, por meio de encontros ${ }^{31}$ promovidos por organizações governamentais, não governamentais, indígenas e não indígenas:

Os Kinikinau, assim como membros de outras sociedades indígenas do Brasil de hoje, não desejam ser chamados de 'ressurgidos', pois entendem que a conotação seja pejorativa e pouco explicativa da situação histórica a que foram submetidos. Preferem, por essa razão, a expressão 'resistentes. ${ }^{32}$

De acordo com algumas lideranças indígenas, a palavra 'resistente' expressaria a ideia de que essas populações não desapareceram, ainda que muitas vezes tenham permanecido ocultas, e enfrentaram os processos de colonização e as presenças de não índios em suas vidas, ora guerreando, negociando, fugindo, capitulando, escondendo-se ou, ainda, fazendo-se passar por Outros. 
Historicamente, há uma ideia de continuidade por trás da expressão 'resistente', estrategicamente utilizada pelos grupos na afirmação de suas respectivas identidades étnicas. A sobrevivência de inúmeras etnias, em meio ao desaparecimento físico e cultural de tantas outras no Brasil, somente na primeira metade do século XX (cf. Ribeiro, 1970), demonstra a força dessa e de outras populações indígenas, tais como os Guató, os Kinikinau e os Ofayé, que já figuraram na lista dos grupos 'extintos', como foi citado.

Aliás, Mato Grosso do Sul é um dos estados em que há intensos e contínuos conflitos entre fazendeiros e indígenas, situação que se arrasta, pelo menos, desde o século XIX. Compreender a situação das diversas sociedades indígenas presentes no antigo sul do Mato Grosso não é tarefa das mais simples, uma vez que, ao longo do tempo, essas populações estiveram submetidas a um gradativo e violento processo de fixação em pequenas porções de terras. $\grave{A}$ exceção dos Kadiwéu, que possuem o usufruto de mais de meio milhão de hectares demarcados entre o início do século XX e a década de $1980,{ }^{33}$ os demais grupos lutam para reaver territórios tradicionais, usurpados há tempos e ocupados por fazendeiros, posseiros, grileiros etc.

Assim, os Ofayé, Terena, Guarani-Kaiowá, Guarani-Ñandeva e Guató vivem em áreas reservadas pelo governo federal, algumas delas passando atualmente por processos de revisão, para possível ampliação. Já os Chamacoco (também chamados de Ishir) vivem boa parte do tempo no Paraguai, em aldeias próprias, migrando sazonalmente para terras brasileiras. Além disso, os Atikum, oriundos de Pernambuco, encontram-se em terras dos índios Terena, no município de Nioaque, desde meados da década de 1980, e os Kinikinau sofreram uma verdadeira 'diáspora', espalhando-se por áreas indígenas ainda na primeira metade do século XX. Os dois últimos grupos citados estão, no momento, mobilizados na reivindicação junto ao órgão indigenista oficial pela conquista de um território que lhes seja próprio. Há, ainda, os que sequer possuem o usufruto de terras consideradas indígenas, como é o caso dos Kamba ou Camba-Chiquitano, além dos Layana, Guaná e outros.

Aprender a respeito dessa rica riquíssima diversidade étnica e cultural constitui-se em desafio permanente para professores e estudantes da Educação Básica no Brasil e, particularmente, em Mato Grosso do Sul. Poucas são as obras e textos que tratam genericamente das questões indígenas, sem resvalar na estereotipagem. Há exceções, tais como Breve Painel Etno-Histórico de Mato Grosso do Sul, do historiador e arqueólogo Gilson Rodolfo Martins, ${ }^{34}$ e Povos 
Indígenas no Mato Grosso do Sul: viveremos por mais 500 anos, lançado em 1993 pelo pesquisador Olívio Mangolim. ${ }^{35}$ Além desses, os textos "Línguas indígenas em Mato Grosso do Sul, Brasil: entre a insistência da manutenção e a iminência da desaparição", de autoria de Giovani José da Silva, ${ }^{36}$ e "Sujeitos e saberes da Educação Indígena" ${ }^{37}$ são uns dos poucos a tratarem das questões indígenas em Mato Grosso do Sul para um público não especializado. Aumentar o número de obras desse gênero é também um desafio a ser enfrentado pelos pesquisadores no diálogo com aqueles que trabalham e estudam na Educação Básica em todo o Brasil.

\section{NOTAS}

${ }^{1}$ Cf. em www.ibge.gov.br.

${ }^{2}$ RICARDO, C. A.; RICARDO, F. (Ed.). Povos indígenas no Brasil 2006/2010. São Paulo: Instituto Socioambiental, 2011. 763p.

${ }^{3}$ LOPES DA SILVA, A. (Org.). A questão indígena na sala de aula: subsídios para professores de $1^{\circ}$ e $2^{\underline{0}}$ graus. São Paulo: Brasiliense, 1987. 253p.

${ }^{4}$ GRUPIONI, L. D. B. (Org.). Índios no Brasil. Brasília: MEC, 1994. 279p.

${ }^{5}$ LOPES DA SILVA, A.; GRUPIONI, L. D. B. (Org.). A temática indígena na escola: novos subsídios para professores de 1ํ e 2ํㅡㅁ graus. Brasília: MEC/Mari; São Paulo: Ed. USP, 1995. 575 p.

${ }^{6}$ MELATTI, J. C. Índios do Brasil. 7.ed. São Paulo: Hucitec; Brasília: Ed. UnB, 1993. 220p. O antropólogo, professor da UnB (Universidade de Brasília), mantém um site, conhecido como "página do Melatti", em que o leitor poderá encontrar informações atualizadas a respeito das sociedades indígenas nas Américas: www.juliomelatti.pro.br/. Além disso, John Manuel Monteiro, historiador e professor da Unicamp (Universidade Estadual de Campinas), mantém na Internet uma página intitulada "Os índios na história do Brasil": www.ifch.unicamp.br/ihb/.

${ }^{7}$ FERNANDES, J. O indio: esse nosso desconhecido. Cuiabá: Ed. UFMT, 1993. 149p.

${ }^{8}$ CARNeIRO DA CUNHA, M. (Org.). História dos índios no Brasil. São Paulo: Companhia das Letras; SMC; Fapesp, 1992. 611p.

${ }^{9}$ MONTEIRO, John M. Confronto de culturas. In: AZEVEDO, F. L. N. de; MONTEIRO, J. M. (Org.). Confronto de culturas: conquista, resistência, transformação. São Paulo: Edusp, 1997. p.19-20, grifos no original.

${ }^{10}$ LOPES DA SILVA, A.; FERREIRA, M. K. L. (Org.). Antropologia, história e educação: a questão indígena e a escola. São Paulo: Global; Fapesp; Mari, 2001a. 396p.; LOPES DA SILVA, A.; FERREIRA, M. K. L. (Org.). Práticas pedagógicas na escola indígena. São Paulo: Global; Fapesp; Mari, 2001b. 378p.; FERREIRA, M. K. L. (Org.). Ideias matemáticas de 
povos culturalmente distintos. São Paulo: Global, 2002. 336p.; e LOPES DA SILVA, A.; MACEDO, A. V. L. da S.; NUNES, Â. (Org.). Crianças indígenas: ensaios antropológicos. São Paulo: Global; Fapesp; Mari, 2002. 280p.

${ }^{11}$ ALMEIDA, M. R. C. de. Os índios na história do Brasil. Rio de Janeiro: Ed. FGV, 2010. $167 \mathrm{p}$.

${ }^{12}$ FUNARI, P. P.; PIÑON, A. A temática indígena na escola: subsídios para professores. São Paulo: Contexto, 2011. 128p.

${ }^{13}$ Cf. www.socioambiental.org.br.

${ }^{14}$ RIBEIRO, D. Os índios e a civilização: a integração das populações indígenas no Brasil moderno. Rio de Janeiro: Civilização Brasileira, 1970. 495p.

${ }^{15}$ MONTEIRO, John M. O desafio da história indígena no Brasil. In: LOPES DA SILVA, A.; GRUPIONI, L. D. B. (Org.). A temática indígena na escola: novos subsídios para professores de 1ํ e 2o graus. Brasília: MEC/Mari; São Paulo: Ed. USP, 1995, p.221-228. p.222.

${ }^{16}$ SCHADEN, E. Aculturação indígena. São Paulo: Pioneira, 1969. 334p.

${ }^{17}$ OLIVEIRA, J. P. de (Org.). A viagem da volta: etnicidade, política e reelaboração cultural no Nordeste indígena. 2.ed. Rio de Janeiro: Contracapa, 2004. 361p.

${ }^{18}$ RICARDO, C. A. (Ed.). Povos indígenas no Brasil 1991-1995. São Paulo: Instituto Socioambiental, 1996. 871p.; RICARDO, C. A. (Ed.). Povos indígenas no Brasil 1996-2000. São Paulo: Instituto Socioambiental, 2000. 831p.; RICARDO, C. A.; RICARDO, F. (Ed.). Povos indígenas no Brasil 2001-2005. São Paulo: Instituto Socioambiental, 2006. 879p.; e RICARDO; RICARDO, 2011, cit.

${ }^{19}$ JOSÉ DA SILVA, G. (Org.). Kadiwéu: senhoras da arte, senhores da guerra. Curitiba: CRV, 2011.211p.

${ }^{20}$ SANDALO, F. Estratificação social e dialetos prosódicos na língua Kadiwéu. In: JOSÉ DA SILVA (Org.), 2011. p.149-161.

${ }^{21}$ BITTENCOURT, C. M. F. O ensino de História para populações indígenas. Em Aberto, Brasília, ano 14, n.63, p.105-116, jul.-set. 1994.

${ }^{22}$ JOSÉ DA SILVA, G.; LACERDA, L. T. A educação escolar indígena em perspectiva histórica: os Kadiwéu e a "pedagogia da violência" (segunda metade do século XX). In: CONGRESSO BRASILEIRO DE HISTÓRIA DA EDUCAÇÃO, 3., 2004, Curitiba. Anais... Curitiba: Pontifícia Universidade Católica do Paraná, 2004.

${ }^{23} \mathrm{O}$ uso dessa expressão era comum entre os Kadiwéu ao se referirem à escola dos 'tempos de antigamente'. Nota-se que na tradição oral Kadiwéu, o cemitério (apiigo) é um lugar indesejado, posto que seja o local das almas errantes, o que torna bastante interessante (e intrigante) a representação.

${ }^{24}$ Cf. PECHINCHA, M. T. S. Histórias de admirar: mito, rito e história Kadiwéu. 1994. 202 f. Dissertação (Mestrado em Antropologia Social) - Universidade de Brasília (UnB). Brasília, 1994. 
${ }^{25}$ JOSÉ DA SILVA, G. Notícias da guerra que não acabou: a Guerra do Paraguai (18641870) rememorada pelos índios Kadiwéu. Fronteiras, Dourados, v.9, n.16, p.83-91, 2007.

${ }^{26}$ Tal categoria foi sugerida informalmente pelo prof. dr. John Manuel Monteiro, da Unicamp, durante o XXIII Simpósio Nacional de História, em jul. 2005, na Universidade Estadual de Londrina (UEL). Desde então o autor vem procurando desenvolver tal ideia (JOSÉ DA SILVA, 2007).

${ }^{27}$ TASSINARI, A. M. I. Escola indígena: novos horizontes teóricos, novas fronteiras de educação. In: LOPES DA SILVA; A.; FERREIRA, M. K. L. (Org.). Antropologia, história e educação: a questão indígena e a escola. São Paulo: Fapesp; Global; Mari, 2001. p.44-70.

${ }^{28}$ BORGES, P. H. P. Ymã, ano mil e quinhentos: relatos e memórias sobre a conquista. Campinas (SP): Mercado das Letras; Cascavel (PR): Unipar, 2000, 168p. p.14.

${ }^{29}$ MONTEIRO, J. M. Armas e armadilhas: história e resistência dos índios. In: NOVAES, A. A outra margem do Ocidente. São Paulo: Companhia das Letras, 1999, p.237-249. p.247.

${ }^{30}$ JOSÉ DA SILVA, G. A presença Camba-Chiquitano na fronteira Brasil-Bolívia (19381987): identidades, migrações e práticas culturais. 2009. 291f. Tese (Doutorado em História) - UFG (Universidade Federal de Goiás). Goiânia, 2009.

${ }^{31}$ Dentre outros importantes encontros, citam-se o "I Encontro Nacional dos Povos Indígenas em Luta pelo Reconhecimento Étnico e Territorial” (Olinda, PE, 15 a 19 maio 2003) e o “Seminário dos Povos Resistentes: a presença Indígena em MS” (Corumbá, MS, 10 a 12 dez. 2003).

${ }^{32}$ JOSÉ DA SILVA, G.; SOUZA, J. L. de. O despertar da fênix: a educação escolar como espaço de afirmação da identidade étnica Kinikinau em Mato Grosso do Sul. Sociedade e cultura, Goiânia, v.6, n.2, p.149-156, 2003. p.155.

${ }^{33}$ JOSÉ DA SILVA, G. A construção física, social e simbólica da Reserva Indígena Kadiwéu: memória, identidade e história. 2004. 144f. Dissertação (Mestrado em História) - UFMS (Universidade Federal de Mato Grosso do Sul), Campus de Dourados. Dourados, 2004.

${ }^{34}$ MARTINS, G. R. Breve painel etno-histórico de Mato Grosso do Sul. 2.ed. rev. e ampliada. Campo Grande: UFMS, 2002. 98p.

${ }^{35}$ MANGOLIM, O. Povos indígenas em Mato Grosso do Sul: viveremos por mais 500 anos. Campo Grande: Cimi/MS, 1993. 119p.

${ }^{36}$ JOSÉ DA SILVA, G. Línguas indígenas hoje em Mato Grosso do Sul, Brasil: entre a insistência da manutenção e a iminência da desaparição. In: SOUZA, A. A. A. de; FRIAS, R. B. (Org.). O processo educativo na atualidade: fundamentos teóricos. Campo Grande: Uniderp, 2005. p.183-192.

${ }^{37}$ JOSÉ DA SILVA, G.; LACERDA, L. T.; NINCAO, O. S. Sujeitos e saberes da Educação Indígena. In: LACERDA, L. T.; PINTO, M. L. (Org.). Educação, diversidade e cidadania: sujeitos e saberes dos processos e das práticas pedagógicas. Dourados: UEMS, 2011. p.87-98.

Artigo recebido em 20 de junho de 2012. Aprovado em 1ํ de setembro de 2012. 